\title{
RELACIONES ENTRE LA HISTORIA DE LA FILOSOFÍA Y LA FILOLOGÍA CON BASE EN EL LIBRO PLAUTO Y DESCARTES ${ }^{1}$
}

\author{
$\mathrm{M}^{\mathrm{a}}$ Isabel LAFUENTE GUANTES \\ Universidad de León
}

\begin{abstract}
RESUMEN: En este artículo se analizan las relaciones entre Historia de la Filosofía y Filología a partir de la consideración de la obra de Descartes como reproductora de los esquemas del teatro de Plauto. Se muestra la imposibilidad de reducir esta filosofía a sus fuentes filológicas, así como las formas de considerar las fuentes, los problemas que ello involucra y cómo entender el humanismo en la obra cartesiana.
\end{abstract}

PALABRAS CLAVE: Historia de la Filosofía, fuentes, razón, objetividad, humanismo.

ABSTRACT: In this paper the relations between History of the Philosophy and Philology are analyzed starting from the consideration of the work of Descartes as a reproduction of the schemes of Plauto's theatre. It is shown that it is impossible to reduce this philosophy to its philological sources, as well as the ways of considering the sources, the problems that it involves, and how to understand Humanism in Cartesian philosophy.

KEYWORDS: History of Philosophy, sources, reason, objectivity, Humanism.

\section{INTRODUCCIÓN}

Siempre ha sido difícil entender las relaciones entre Filosofía y Filología. Es claro que hacer filosofía, dado que su forma de expresión es el lenguaje, y tiene que contar con otros lenguajes, supone conocimientos filológicos aunque sean elementales; en la Historia de la Filosofía estos conocimientos resultan más necesarios, sobre todo al hacer o trabajar con la Historia de la Filosofía Filológica, tanto en un sentido técnico, como en un sentido cultural ${ }^{2}$. La Historia de la Filosofía es, ciertamente, un campo de encuentro de filósofos y filólogos.

${ }^{1}$ Recibido el 30 de junio de 2011. Aceptado en el Consejo de 8 de noviembre de 2011.

${ }^{2}$ En Teoría y Metodología de la Historia de la Filosofía, he distinguido entre cuatro tipos de Historia de la Filosofía: Filosófica-Técnica, Filosófica-Cultural, Filológico-Técnica, Filológico- 
El libro Plauto y Descartes ${ }^{3}$, escrito por el Dr. Benjamín García Hernández, es una de las investigaciones en que tiene lugar dicho encuentro en la obra de un filólogo que, por su temática y buen trabajo, es sumamente pertinente para considerar la forma de las relaciones entre la Historia Filosofía y la Filología. En esta obra se trata de probar que la fuente de inspiración del sistema filosófico de Descartes, se halla en una comedia, o aún mejor tragicomedia, de Plauto: Amphitrio, Amphitruo o Anfitrión. La importancia del trabajo que se propone realizar: mostrar la dependencia que la obra de Descartes tiene de una teatral cuyo sello la ha marcado de forma indeleble ${ }^{4}$, aunque el autor lo haya ocultado siempre, presenta relativamente a la Historia de la Filosofía dos alternativas que es necesario dilucidar: saber si esta consideración hace variar la interpretación filosófica de la obra cartesiana y en qué aspectos, y/o si hace variar su situación en el contexto cultural.

\section{LA FICCIÓN Y LA OBRA CARTESIANA}

No es nueva la consideración de Descartes desde la perspectiva teatral, se puede recordar el título de la obra de M. Leroy: Descartes filósofo enmascarado ${ }^{5}$, así como recoger apreciaciones continuas que él mismo hace en sus obras sobre la ficción, el fingir, etc. por ejemplo cuando dice:

"Posteriormente, examinando con atención lo que yo era, y viendo que podía fingir que carecía de cuerpo así como que no había mundo o lugar alguno en el que me encontrase...". 6

Hay interpretaciones de la filosofía cartesiana que hacen pensar que Descartes, más que intentar leer en el gran libro del mundo ${ }^{7}$ para conocer qué impedía lograr una verdad segura, objetiva, y la forma de establecerla, lo que aprendió, y a lo que da lugar en sus obras, es a toda suerte de escenas artificiosas con las que mostrar en qué consiste el Gran Teatro del Mundo, en el que tiene lugar la representación de

Cultural. Cfr.: Lafuente, M. I. (1987). Teoría y Metodología de la Historia de la Filosofía. Universidad de León: Contextos, pp. 64-73.

${ }^{3}$ García Hernández, B. (1997). Plauto y Descartes. Madrid: Tecnos. En las referencias a esta obra, se sigue la edición citada. El Dr. Benjamín García Hernández fue Catedrático de Latín en la Universidad de León y actualmente lo es en la Universidad Autónoma de Madrid.

${ }^{4}$ Cfr.: García HeRnÁndeZ, B.: Op. Cit., p. 238.

${ }^{5}$ LEROY, M. (1930). Descartes: El filósofo enmascarado. Madrid: Espasa-Calpe.

6 Descartes, R. (1981). Discurso del Método, p. 25. Madrid: Alfaguara. A-T. VI, 33-34. Esta obra se cita siempre por esta edición, y con la referencia a la de: ADAM \&TANNERY (1982). Vol. VI. París: Vrin.

${ }^{7}$ Expresión que usa Descartes en el Discurso del Método, p. 9. A-T. VI, 9. 
la vida de unos seres (los humanos) cuyos papeles son distribuidos por Dios. Realmente contra esta concepción dramática de la obra de este autor no valen argumentos que muestren que su preocupación por la ficción no es esa, sino más bien la de no dejar resquicio alguno a los escépticos (y al escepticismo) y que, por ello, la duda cartesiana tiene que considerarse metódica, no escéptica. ${ }^{8}$ También es cierto que algunos de sus objetores tomaron y explotaron la línea de la argumentación retórica y teatral que, como no se deja de poner de relieve en el libro, es rechazada por Descartes.

Ciertamente el lenguaje cartesiano ya no es el escolástico, y sus planteamientos de temas como la duda o la veracidad del autor del mundo dio, y sigue dando, lugar a interpretaciones en las que se tratan como argumentaciones retóricas, sin argumentos consistentes y, por tanto, ficticias. Tal es, por ejemplo, la consideración de Mersenne en las Segundas Objeciones:

“...negáis que Dios sea capaz de mentir o fraude; aunque, con todo, no faltan escolásticos que sostienen lo contrario, como Gabriel, o el Ariminense, y algunos otros, los cuales piensan que, absolutamente hablando, Dios miente; es decir, que transmite a los hombres alguna cosa en contra de su propia intención, y transgrediendo lo que El mismo ha decretado y resuelto, como cuando, por medio de su Profeta, dice a los de Nínive, sin añadir condición alguna: Dentro de cuarenta días, Nínive será destruida " ${ }^{10}$

En este mismo sentido, en las Séptimas Objeciones, el jesuita P. Bourdin, en la tercera de las cuestiones: ¿cómo debe considerarse falsa una cosa?, pone de manifiesto uno de los temas contra el que Descartes lucha denodadamente en su obra: da igual que algo sea verdad, con tal de que no se acepte como tal:

${ }^{8}$ Cuando Descartes afirma la primera verdad de su filosofía, lo hace porque le parece que no queda ningún resquicio para el escepticismo: "Y dándome cuenta de que esta verdad: pienso, luego soy, era tan firme y tan segura que todas las más extravagantes suposiciones de los escépticos no eran capaces de hacerla tambalear, juzgué que podía admitirla como el primer principio de la filosofía que buscaba". Descartes, R.: Discurso del Método, p. 25. A-T.VI, 32. En las Meditaciones: "Pues bien: es certísimo que ese conocimiento de mí mismo, hablando con precisión, no puede depender de cosas cuya existencia aún me es desconocida, ni por consiguiente, y con mayor razón, de ninguna de las que son fingidas e inventadas por la imaginación". DESCARTES, R. (1977). Meditaciones Metafísicas. Madrid: Alfaguara, p. 26. A-T.VII, 19-20. Esta obra se cita siempre por esta edición, y con la referencia a la de: Adam \&Tannery (1973). Meditationes de Prima Philosophia. Vol. VII. París: Vrin.

${ }^{9}$ En el libro se dedica en el apartado C de la parte II, dos capítulos a presentar los testimonios directos e indirectos de la clave dramática de la filosofía cartesiana. Cfr.: GARCía HERnández, B.: Op. Cit, pp. 168-200.

${ }^{10}$ Descartes, R.: Meditaciones Metafísicas. (Segundas Objeciones), p. 104. A-T. VII, 136-137. 
"Tener una cosa por falsa significa no dar aprobación a dicha cosa, como si fuera manifiestamente falsa, e incluso fingir que se tiene de ella la misma opinión que de una cosa falsa e imaginaria". 11

El resultado de esta forma de considerar problemas como la duda, el conocimiento, la veracidad divina, etc., según se muestra claramente en algunas de las objeciones, es que el ser humano es un ser totalmente indefenso frente a un Dios omnipotente y mentiroso, y que ninguna seguridad puede esperar del contexto humano, pues éste es réplica de la mentira divina. Al ser humano, en este mundo, sólo le es posible: o el fingimiento, frente a la burla divina que percibe aunque sea de forma confusa, o una fe ciega, y tan ciega que sólo la guía su propia voluntad. El mundo resulta una ratonera cruel que no merece existir.

No cabe duda que la filosofía cartesiana permite entender el mundo como la obra de un autor divino, pero tampoco cabe la menor duda de que su resultado no es el que corresponde a la idea de un mundo burlesco y cruel, lo que no quiere decir que no sea la de un mundo difícil. Por ello, no es de extrañar que el mismo Bourdin, a quien se debe el tono más burlesco y teatral de las objeciones, tal vez intentado que no recaiga sobre él la percepción del mundo bajo semejante perspectiva, sino que se considere que nace del mismo planteamiento cartesiano, termine sus objeciones con las siguientes apreciaciones:

"Decidme, os lo ruego: ¿por qué negáis esto: yo tengo un cuerpo? Sin duda es porque dudáis de ello. Pero ¿no es tan dudoso esto otro: yo no tengo cuerpo? ¿Habrá alguien, a poco discreto que sea, que quiera poner como fundamento de la ciencia, y de una ciencia -además- que se tiene por más segura que las otras, algo que no sin razón puede considerar falso? Más ya basta. Quiero detenerme aquí, poniendo fin a estos errores. Y a la pregunta que me habéis hecho (a saber: si es buen método, en filosofía, rechazar todas aquellas cosas de que puede dudarse), responderé, según deseabais, con palabras honestas, libres y sin disfraz". ${ }^{12}$

Por lo que tampoco extraña que Descartes inicie su respuesta como sigue:

"El Reverendo Padre ha hablado hasta ahora con disfraz de burla; como parece que, en adelante, va a cambiar de máscara y hablar en serio, diré aquí en pocas palabras lo que a cuento de sus burlas he observado". ${ }^{13}$

\footnotetext{
${ }^{11}$ Ibid. (Séptimas Objeciones), p. 347. A.T. VII, 13, p. 459.

12 Ibid. (Séptimas Respuestas), p. 387. A-T. VII, Tt. 75, p. 508.

${ }^{13}$ Ibid.
} 
En lo que respecta al conocimiento que Descartes pudo tener de la obra de Plauto, se aportan numerosas pruebas relativas a las representaciones de la obra en la época y en el Colegio de Jesuitas de La Flêche. Ahora bien, la prueba justificativa del conocimiento que Descartes pudo tener de la obra de Plauto es la narración que del tercero de los sueños, el que tuvo el 10 de noviembre de 1619, hizo el propio Descartes en su obra las Olímpicas, hoy perdida, y que recoge su biógrafo Baillet, quien dice haberla tomado del propio autor. En este sueño Descartes cita la colección de poesías denominado Corpus Poetarum, del que escribe García Hernández:

"Se trata de una obra, en dos gruesos volúmenes, confeccionados por Pierre de Brosses (Petrus Brossaeus), editada primero en Lyon en 1603 y luego en Ginebra en 1611". ${ }^{14}$

En esta obra, que contiene la mayor parte de la poesía latina, se presenta como primera composición completa el Amfitrión de Plauto. El autor considera este dato suficiente justificación de que Descartes conocía esta obra, que había tenido acceso a ella directamente, y de que no sólo tuvo noticias fragmentarias de ella a través del desarrollo del teatro en el colegio de los jesuitas. En la justificación de que Descartes conocía la obra de Plauto se apoya la tesis de que el Amfitrión es una pieza clave en el desarrollo de las investigaciones sobre las obras que pudieron servir de inspiración al sistema cartesiano, y el propósito de saber sobre el alcance e importancia que se le puede conceder a ésta. Este es el tema fundamental del libro, cuyo subtítulo es: La concepción dramática del sistema cartesiano. Vamos a exponer resumidamente su contenido, sólo para introducir al lector en el tema.

Está dividido en tres partes, en la primera, titulada: El sistema filosófico de Descartes, se recoge el proceso de duda al que el propio Descartes somete el conocimiento en sus Meditaciones Metafísicas. Consiste en un resumen de las seis Meditaciones, en el que se muestra amplia y ordenadamente cual es el camino seguido por Descartes al dar cuenta de su sistema. El resumen sigue un esquema tradicional, pero tampoco pretende más el autor, que evidentemente lo usa para que sirva de información y de ordenación del texto de Descartes.

En esta parte destaca la estructura que se atribuye a la obra cartesiana. Su búsqueda toma como base una obra fragmentaria, la Investigación sobre la verdad, que se entiende contiene el esbozo del sistema que es resumido en la Cuarta Parte del Discurso del Método, y desarrollado en las Meditaciones ${ }^{15}$. Se sostiene que el

\footnotetext{
${ }^{14}$ García HernándeZ, B.: Op. Cit., p. 276.

${ }^{15}$ Cfr.: Ibid., p. 62
} 
sistema filosófico cartesiano tiene una estructura bipartita consistente en: una primera fase (las tres primeras Meditaciones) de conquista de la verdad, que se considera fase ascenso a la contemplación de Dios, y una segunda fase, fase de consolidación, que se hace equivalente al descenso a la observación del mundo (las tres últimas Meditaciones); en la primera fase se va del alma a Dios, y en la segunda se progresa de Dios al mundo ${ }^{16}$.

La consolidación de la estructura del sistema se busca en los elementos de la lengua, y se cifra sobre todo en el sentido conclusivo presente en la redacción de la Meditación Tercera, que se advierte en:

“...el uso del verbo concluir, que sólo aparece antes a propósito de una conclusión particular en el famoso ejemplo de la cera". ${ }^{17}$

El autor considera que en la expresión cartesiana "...hay que concluir que Dios necesariamente existe”, el verbo concluir adquiere valor demarcativo, que es el que permite presentar a Dios como punto culminante del sistema. ${ }^{18}$ La búsqueda y análisis de otros elementos de la lengua con el mismo valor en el sistema, le lleva a poner de relieve, entre otros, el uso del plural en la Cuarta Meditación.

En el campo de la relación lenguaje-conocimiento destacan, entre los análisis que se realizan, los que nos permiten saber sobre: las relaciones demarcativas, es decir, las estructuras de pensamiento elementales contenidas en la obra cartesiana. El autor pone de relieve la existencia de tres estructuras: 1. Secuencias intersubjetivas de pensamiento (Ej. la secuencia buscar-encontrar). 2. Relaciones intersubjetivas alternas (Ej. la secuencia falsedad/verdad). 3. Relaciones complementarias (por Ej. Dios/existencia :: monte/valle). En estos análisis el autor nos va mostrando la riqueza de los temas de la exposición cartesiana accesibles desde el lenguaje.

La segunda parte del libro que se titula: Amphitruo de Plauto, fuente genuina del sistema cartesiano, comienza recogiendo el argumento de la obra de Plauto, que resumo también muy brevemente. Amphitruo, quizá la comedia más importante de Tito Macio Plauto, autor latino que desarrolló su actividad literaria entre fines del siglo III y principios del siglo II a.C., es una comedia burlesca de personajes dobles en la que se representa cómo Mercurio y Júpiter adoptan la forma del general Amphitruo y de su siervo Sosias, y, haciendo de dioses

\footnotetext{
${ }^{16}$ Cfr.: Ibid., p. 62-72.

${ }^{17}$ Cfr.: Ibid., p. 67.

${ }^{18}$ Cfr.: Ibid., p. 68.
} 
burladores y engañadores, se hacen pasar por ellos. Pero la suplantación tiene una finalidad, obedece a que Júpiter se ha enamorado de Alcmena, esposa de Amphitruo, con la que tendrá una relación, haciéndose pasar por su esposo, que dará lugar al nacimiento de dos gemelos, uno de los cuales es Hércules. Esta obra dio lugar a una tradición importante que desde la obra de Routroux de 1636, siguiendo con la de Moliere de 1668 y von Kleist de 1807, llega hasta la de Girandoux de 1929.

El Anfitrión de Plauto presenta como argumento principal el enamoramiento de Júpiter, pero considera como argumentos fundamentales el engaño de los dioses y, sobre todo, la conversión de Júpiter, de dios engañador en dios veraz, al que muestra como verdadero deus ex machina. Como consecuencia del engaño de los dioses, el Anfitrión presenta la profunda crisis de identidad personal de Sosias, el siervo que al ser suplantado por Mercurio, quien le roba su experiencia y su cuerpo, cae en una profunda y total crisis personal, de la que sólo alcanza a salir mediante la reflexión que el ataque violento de Mercurio le lleva a realizar: quien soy, sino el que era.

En esta segunda parte se trabaja sobre la dependencia argumental y expresiva que del Anfitrión de Plauto tienen tanto el proceso de duda de Descartes, como la resolución de la duda en el cogito, la primera verdad; se estudia igualmente la dependencia que de la obra latina tienen las ideas cartesianas del dios engañador y del veraz, garantía este último de la verdad de nuestro conocimiento del mundo.

En sus análisis se muestran las características dramáticas de la duda cartesiana, puestas ya de relieve por Leibniz, De Finance, Maritaine, Champigny, pero no se tiene en cuenta, sin embargo, que resaltar estas características sirvió para iniciar un proceso de acoso a la base del sistema cartesiano, que se decantó en la idea de que usar la duda como método, es hacer de la duda una ficción. Esta tradición sólo tuvo utilidad cuando fue retomada por G. Pierce, quien, al entender que la duda metódica era una duda voluntaria $y$, por tanto, inadmisible, pues, no se puede promover voluntariamente un estado de duda, la usó como argumento para una nueva concepción de la verdad, que dio lugar al gran desarrollo del pragmatismo.

Descartes es un filósofo del Siglo XVII, por lo que en su planteamiento de la duda no pudo ni sospechar el rumbo que podía tomar siglos después, lo que muestra que al considerar las interpretaciones de un concepto no se puede perder de vista la cuestión de su validez en el sistema filosófico que lo propone como fundamento. Por ello no puede obviarse que en la raíz del sistema cartesiano el engaño de los sentidos no es algo fingido (por mucho de Descartes repita esta palabra), ni dudar de ellos algo voluntario, sino algo que tiene lugar si no se acepta 
la independencia de la construcción matemática de su representación sensible ${ }^{19}$, y que es a Descartes a quién se debe el descubrimiento de su solución. En las respuestas a las Quintas Objeciones, las realizadas por Gassendi, el tema está totalmente claro en lo que respecta tanto a las intenciones, como al contenido:

"1. Seguís aquí divirtiéndoos con los fingimientos y disfraces retóricos, en vez de ofrecernos sólidas razones; pues suponéis que hablo de burlas cuando hablo de veras, y en cambio tomáis en serio lo que sólo he propuesto a modo de interrogación y siguiendo la opinión vulgar. En efecto, cuando he dicho que había que tener por inseguros, y hasta por falsos, todos los testimonios que recibimos de los sentidos, lo he dicho en serio; y ello era tan necesario para entender mis Meditaciones, que quien no quiera o no pueda admitirlo no podrá decir al respecto nada que merezca respuesta."20

En este contexto, negar a la duda el valor de principio y base del conocimiento, presentarla como un efecto teatral, como una duda voluntaria alejada de toda realidad, y hacer del proceso de duda un proceso ficticio, es al mismo tiempo entender que no es necesario salir de las representaciones sensibles, y negar la necesidad de progreso en la ciencia. No se puede olvidar que cuando Descartes escribe el Discurso del Método, está elaborando las reglas para establecer un nuevo método científico que permita consolidar las ciencias y propiciar su progreso, basándose en que eliminar el engaño de los sentidos le ha permitido descubrir un criterio con el que asegurar la verdad.

En esta segunda parte, se muestra también la dependencia cartesiana de los elementos escépticos presentes en la obra de Plauto, por ejemplo, la loa del valor de Alcmena, que se sostiene repercutirán en la obra de Francisco Sánchez, Charron y Montaigne, representantes de una tradición escéptica muy importante para la obra cartesiana. Se consideran igualmente las relaciones entre el Dios cristiano de Descartes y los dioses de Plauto. En el capítulo B5, dedicado a las funciones actanciales, se analizan las funciones respectivas de los agentes que intervienen en la acción en ambas obras, poniendo de relieve sus semejanzas y diferencias, por ejemplo, el paso a primer término en la obra de Descartes de la duda y el engaño, frente a la acción amorosa del Anfitrión.

${ }^{19}$ En las Respuestas a las Quintas Objeciones, Descartes defiende la existencia de esencias matemáticas considerándolas como límites en los que están contenidas las sustancias (no sustancias), lo que le permite sostener que no formamos las figuras geométricas a partir de lo sensible, pues en lo sensible no hay ni una línea recta geométrica, sino que conocemos las representaciones sensibles de las figuras geométricas porque tenemos su idea. Cfr. Descartes, R.: Meditaciones Metafísicas, pp. 298-300. A-T, VII,

${ }^{20}$ Descartes, R.: Meditaciones Metafísicas. (Quintas Respuestas), p. 279. A-T. VII, 410-411. 
Finalmente se exponen las claves dramáticas de la filosofía cartesiana y se reitera, y pone de relieve, que como Descartes siempre ocultó celosamente sus fuentes, nunca se llegó a sospechar que pudiera haberse inspirado en Plauto, tema respecto del que el único testimonio directo es Vico que, sin embargo, se limitó a señalar el paralelismo entre ambas obras como su forma de relación.

En la tercera parte, se examina la formación teatral de Descartes entendiéndola como característica de la educación moderna, sobre todo Barroca, promovida muy especialmente en los colegios de jesuitas. Luego se muestra el lugar del teatro de Plauto en esa educación, tras lo que el autor nos lleva a un final en el que se ponen de relieve las condiciones teatrales de la obra cartesiana, desde el larvatus prodeo, hasta los sueños cartesianos, cuyo origen es el Anfitrión de Plauto.

\section{LA FICCIÓN IMPOSIBLE: LOS PROBLEMAS FILOSÓFICOS Y SU SOLUCIÓN}

Hasta el momento he presentado algunos de los análisis y resultados de mérito indudable (hay muchos más, pero he resumido el contenido al máximo), que pertenecen a la obra del Dr. García-Hernández y he considerado algunos problemas generales que la orientación filológica presenta. Pero dado que la obra y pensamiento de Descartes han sido objeto de estudio durante generaciones de filósofos e historiadores de la filosofía, y que ésta consideración hace resurgir algunos problemas que la tradición filosófica ha dejado irresueltos, y tampoco los resuelve, sino que en todo caso muestra su lugar desde el punto de vista de la lengua, y porque no podemos, ni debemos, olvidar que se trata del pensamiento de un filósofo, me parece que es necesario atender en concreto al menos a los principales temas filosóficos que llevan a presentar la obra cartesiana como obra de ficción. Son los siguientes:

1. La consideración de la imaginación.

2. El cogito y la garantía divina: La circulatio.

1. La imaginación: El papel que cumple la imaginación en la obra de Descartes es importante, pero en ella no recae la función cognoscitiva determinante. Presentar como fuente de inspiración del sistema cartesiano la obra teatral de Plauto, conduce no sólo a ver la obra cartesiana como una ficción dramática, sino también a sostener que Descartes destacó la importancia de la literatura y el teatro frente a la filosofía. En este sentido se dice al comentar el tercero de los sueños fantásticos en que se dice que Descartes alumbró su filosofía que: 
"En él Descartes exalta el valor de la imaginación y de la poesía sobre la razón y la filosofía, pues estima ante todo las sentencias cargadas de sentido talladas por los poetas". 21

Pocas líneas después, corroborando esta afirmación, se cita un texto de su biógrafo Baillet, que se considera paráfrasis de un fragmento original de Descartes, en que se pone de relieve la fuerza de la imaginación de los poetas, capaces de lograr pensamientos más eficaces que los filósofos por la razón. Es el siguiente:

"Podría parecer sorprendente por qué las sentencias cargadas de sentido se encuentran en los escritos de los poetas, más que en los de los filósofos. La razón es que los poetas han escrito con el entusiasmo de la inspiración y con la fuerza de la imaginación. Hay en nosotros semillas de la ciencia, como chispas en el pedernal, que los filósofos extraen con la razón, pero los poetas las hacen brotar con la imaginación y resultan más brillantes". ${ }^{22}$

Aún no teniendo prevención para aceptar las relaciones entre las obras filológicas y literarias con las filosóficas, no parece fácil de entender el planteamiento en el contexto racionalista cartesiano, pero en una primera aproximación pienso que si esta admiración es algo más que pura retórica y tiene repercusión en su sistema, tendría que encontrarse en sus obras fundamentales. Es verdad que Descartes manifestó en varios textos su interés e inclinación por la literatura, pero lo que sostuvo ante todo es que era fruto del ingenio y no de la razón, y que los que practicaban ésta siempre encontrarían la forma de hacerse comprender:

“Admiraba en alto grado la elocuencia y era un amante de la poesía, pero opinaba que tanto la una como la otra eran cualidades del ingenio más que fruto del estudio. Aquellos que poseen una excelente capacidad para razonar y disponer con orden sus pensamientos con la finalidad de hacerlos claros e inteligentes siempre serán capaces de persuadir sobre el tema que se han propuesto aunque hablen la lengua de la baja Bretaña y jamás hayan estudiado retórica". 23

El ingenio, la imaginación y la retórica exaltados por los renacentistas, para Descartes sólo conducen a creer en ficciones, en héroes de novelas, en hazañas imposibles $^{24}$, y a trazar proyectos irrealizables. De forma consecuente, presenta la

${ }^{21}$ García Hernández, B.: Op. Cit., p. 272.

22 Ibid., p. 273.

${ }^{23}$ Descartes, R.: Discurso del Método, p. 35. A-T. VI, 8-9.

${ }^{24}$ Ibid., p. 36.A-T., VI, 9-10. 
imaginación en su filosofía como la facultad a la que le corresponde permitir la percepción de todas las figuras, de toda variación, pero que es incapaz de realizar una síntesis que las constituya como totalidad. Es al entendimiento a quien le corresponde encontrar la regla capaz de unificar el conjunto de datos amontonados, incomprensibles e inutilizables, que solo pueden ser apreciados imaginativamente. En el célebre texto de la Segunda Meditación, la reflexión sobre el pedazo de cera, cuando Descartes se pregunta cuál es la realidad que le corresponde a la materia y si podemos conocerla por la imaginación, dice:

“...puesto que la concibo (la cera) capaz de sufrir una infinidad de cambios, y esa infinitud no podría ser recorrida por mi imaginación, esa concepción que tengo de la cera no es obra de la facultad de imaginar...Debo, pues, convenir en que yo no puedo concebir lo que es esa cera por medio de la imaginación, y sí sólo por el entendimiento". ${ }^{25}$

La filosofía cartesiana no se apoya en la imaginación, ni la aproxima a la razón. A parte de que Descartes sea el autor de un descubrimiento matemático fundamental, toda su metodología filosófica y científica, necesaria para establecer las condiciones objetivas del conocimiento, se muestra como un proceso constructivo y objetivo, no como un proceso en que la imaginación constituya unos enlaces cuyo valor pueden ser subjetivos y no objetivos.

2. El cogito y la garantía divina. La consideración de la primera verdad del sistema filosófico cartesiano, el cogito, es particularmente complicada de realizar, pues si bien su existencia se afirma como verdad independiente en la fórmula: "cogito, sum", esto no resuelve el problema de garantizar su verdad objetivamente, lo que es acuciante, pues de ello depende poder establecer el principio de evidencia como primera regla del método. La forma en que en el texto de la obra se atiende al cogito, reproduce todos los problemas que en la tradición ha generado su consideración, y que se pasan por alto al aceptar sin más su independencia como principio:

"La existencia de Dios es anterior a la del propio yo pensante; sin embargo, Descartes llega a la certeza de la existencia de Dios, después de haber tomado conciencia de la propia. Así que Dios es garante de toda verdad, pero hay una verdad para la que no ha sido necesario ese aval divino y es el cogito; esta independencia del cogito respecto de la veracidad divina no fue vista por Arnauld en las Cuartas Objeciones". ${ }^{26}$

${ }^{25}$ Descartes, R.: Meditaciones Metafísicas, pp. 28-29. A-T. VII, 23-24.

${ }^{26}$ GARCÍA-HERNÁNDEZ, B.: Ibid., p. 148. 
Considero que es necesario un planteamiento crítico del problema, y éste tiene que contar ineludiblemente con la acusación de incurrir en circulatio que le hizo Arnauld, pues al pasarse por alto se incurre en el error que deriva de esta crítica: dar por bueno el principio y su independencia, sin mostrar su razón:

"Sólo un escrúpulo me resta, escribía Arnauld, y es saber cómo puede pretender no haber cometido círculo vicioso, cuando dice que sólo estamos seguros de que son verdaderas las cosas que concebimos clara $y$ distintamente, en virtud de que Dios existe. Pues no podemos estar seguros de que existe Dios, si no concebimos eso con claridad y distinción; por consiguiente antes de estar seguros de la existencia de Dios, debemos estarlo de que es verdadero todo lo que concebimos con claridad y distinción". ${ }^{27}$

Ciertamente estas palabras hacen suponer que Descartes está considerando la existencia del pensamiento en general, y parecen no tener en cuenta que Descartes no hace equivalente el cogito al pensamiento, por tanto, que no se trata de que todas las cosas que pienso (percibo) clara y distintamente sean verdaderas, sino que, por el contrario, sólo afirma que el hecho de que yo pienso es indudable. Descartar todas estas equivalencias es lo que hace del cogito la primera verdad, pero la acusación de circulatio tiene la virtud de mostrar que el planteamiento cartesiano encierra un problema: el cogito puede resultar una verdad, pero no la primera verdad. Puede ser verdad sólo para mí, para mi conciencia, es decir, una verdad subjetiva $^{28}$, pues hay un prius ontológico, que es Dios, que es quien determina la realidad (existencia) de cualquier referencia objetiva (ontológica) del pensamiento, y sin mostrar que se puede salir del círculo es más bien complicado mantener la existencia del yo pienso como verdad no sólo para mí, es decir, como fundamento de la existencia de verdades objetivas.

El problema de la circulatio, que no se considera así en el libro, consiste en que se está planteando la existencia de dos verdades una gnoseológica y otra ontológica, que se admite la necesidad de primar la última, y que se reconoce que sin existir Dios el cogito no es verdad objetivamente, es decir, que por sí misma la verdad gnoseológica es subjetiva:

"De esta suerte, el cogito es la primera verdad para mí, en el orden gnoseológico, mientras que Dios es la primera verdad en sí, en el orden

27 Descartes, R.: Meditaciones Metafísicas (Cuartas Objeciones), p. 174. A-T. VII, 246-247.

28 El intento de transformas la orientación solipsista del ego cartesiano en Ego puro y trascendental, se debe a Husserl. Cfr.: HusserL, E. (1963). Cartesianische Meditationen. Haag: Martines Nijhoff. Vol. I. 
ontológico. Sin la existencia de Dios no existiría el propio pensamiento, la primera verdad descubierta". ${ }^{29}$

Descartes se dio cuenta del problema que la objeción de Arnauld planteaba, pero rechazó la acusación de incurrir en círculo, y mostró que no le preocupaba. La fórmula que en su obra muestra la razón de su falta de preocupación es: soy una cosa que piensa. Pero introducir el término cosa supone reconocer que la existencia no es, ni puede ser, una condición gnoseológica, sino una realidad ontológica, aunque sea descubierta por el pensamiento, por tanto, que la gnoseología tiene que tener en su base categorías ontológicas: que no se puede separar el pensamiento de la materia. Hobbes increpó a Descartes en sus Objeciones en este sentido:

"Pero ¿de dónde nos viene el conocimiento de la proposición yo pienso? No de otra parte, sin duda, sino de no poder concebir nosotros ningún acto sin sujeto: como el pensamiento sin una cosa que piense, el saber sin una cosa que sepa, o el pasear sin algo que pasee.

Y de ahí parece seguirse que una cosa pensante es algo corpóreo; pues parece que los sujetos de cualquier acción sólo pueden entenderse considerándolos corpóreos o materiales;",30

En el sistema racionalista cartesiano probar la existencia del yo pienso hace preciso distinguir entre pensamiento/materia (espíritu/extensión, cuerpo) y entender que son dos sustancias completas ${ }^{31}$, de forma que cuando se consideran conjuntamente en un ser humano movimiento y pensamiento su unidad tiene que entenderse de composición, y no de naturaleza. ${ }^{32}$ Esto, unido al problema del cogito, hace que todo el sistema de Descartes cobre un aspecto fantasmagórico o teatral, pues de la acusación de circulatio resulta que la verdad fundamental, el cogito, es sólo subjetiva, y cuando se trata de mostrar el yo de forma completa su solución es entender que existen dos sustancias cuya unidad sólo puede pensarse como composición, y ésta sólo depende de que en nuestro pensamiento no exista contradicción $^{33}$, es decir, que percibamos sus elementos de forma clara y distinta.

${ }^{29}$ García-HernándeZ, B.: Op. Cit., p. 48.

30 Descartes, R.: Meditaciones Metafísicas (Terceras Objeciones), p. 141. (En cursiva en la edición). A-T. VII, 194-196.

${ }^{31}$ Cfr.: Ibid. (Cuartas respuestas), p. 181-182. A-T.VII, 254-258.

32 Cfr.: Ibid. (Sextas respuestas), p. 325. A-T. VII, 470-471.

33 La relación entre pensamiento y realidad objetiva, como la presenta Descartes en las Respuestas a las Segundas Objeciones (P. Mersenne), exige tener en cuenta que la contradicción sólo pertenece a nuestro pensamiento y no a la cosa que está fuera de él, que nunca es contradictoria, sino 
Si no hay salida del círculo el sujeto puede constituir la realidad formalmente, pero objetivamente la realidad será sólo posible, salvo por la garantía de la existencia divina; de esta manera incluso Dios aparece como un dios del teatro, el famoso deus ex machina, cuya necesidad se limita a venir a solucionar la puesta en escena de un problema irresoluble.

La tradición de estudiosos de Descartes recoge profusamente el problema básico, la circulatio, pero no lo soluciona. Una autoridad como Laporte dice que Descartes siempre se defendió de no incurrir en petición de principio, pero también afirma que vio el círculo muy claramente y apunto el medio para salir de él:

"Descartes a bien vu le cercle, et nous indique le moyen d'en sortir. Il nous invite a former certaines conceptions sur ce qui, en nous ou dans l'objet, corcerne la connaissance des choses (illud omne quod in nobis est ad res gognoscendas), sans nous soucier pour le moment de savoir si elles répondent à la réalité...". 34

Tras esta apreciación que tiene lugar en el contexto de la aplicación del método a la ciencia, Laporte afirma que las apreciaciones cognoscitivas, y todo el método, tendrán que ser considerados sólo hipótesis cuya legitimación sólo podrá tener lugar en virtud de las verdades que permitan demostrar:

"Ainsi la méthode en son ensemble et avec tous ses réquisits pourra bien être proposée d'abord, mais selement a titre d'hypothèse: l'hypothèse será ensuit légitimée par son succés par les vérites mêmes qu'elle aura servir à découvrir et à démontrer". 35

De acuerdo con esta consideración salir del círculo parece imposible sin aceptar que es verdad todo aquello que en una demostración produce una conclusión fructífera (se supone que mediante la aplicación y cumplimiento de todas las

posible: "Pues toda imposibilidad o contradicción radica sólo en nuestro concepto o pensamiento, que no puede unir las ideas que se contradicen; y no puede radicar en cosa alguna que esté fuera del entendimiento, pues, por el solo hecho de estar fuera del entendimiento, es evidente que dicha cosa no es contradictoria, sino posible." (DESCARTES, R.: Meditaciones Metafísicas. (Segundas Respuestas), p.123. A-T., VII, 168-169.

34 "Descartes ha visto perfectamente el círculo, y nos indica el medio para salir de él. Nos invita a formar algunas concepciones sobre lo que, en nosotros o en el objeto, concierne al conocimiento de las cosas (todo lo que en nosotros es el conocimiento de la cosa), sin preocuparnos por el momento de saber si responden a la realidad". LAPORTE, J. (1950). Le rationalisme de Descartes. París: Vrin, p. 2.

35 "Así, el método en su conjunto, y todos sus requisitos pueden ser propuestos desde el inicio, pero solamente a título de hipótesis: la hipótesis será legitimada después por su éxito respecto a las verdades que puede permitir descubrir y demostrar" Ibid., pp. 2-3. 
reglas), pues en ello se muestra su utilidad. Pero, entonces, el problema filosófico queda sin resolver, y nos encontramos con un método hipotético y unas verdades supuestas (hipótesis) que sólo serán legítimos si pueden dar lugar a una demostración en la que ellos mismos se producen como verdad. Y ¿qué permite afirmar que la verdad producida lo es?, parece que sólo su utilidad, pero como ésta no permite salir del contexto de la demostración realizada, el método y su principio quedan sin garantía, y Descartes pretende mostrar que la tiene, pues probarlo filosóficamente es la única forma de poder extenderlo a todas las ciencias, como pretende realizar según la exposición del Discurso del Método.

Parece que atender en sus términos esenciales al círculo que se plantea entre cogito y veracidad divina lo muestra como insalvable, pues afirmar la primera verdad, cuando ésta va a ser el fundamento del método, no sólo exige probar que Dios existe, sino que es verdadero. Sólo esta última condición autoriza a afirmar que todo lo que percibo con claridad y distinción es verdadero, pero la prueba tiene que contar y superar la tesis del deus deceptor, filosóficamente aceptada desde Ockham por la tradición nominalista, cuya existencia no permite garantizar ninguna verdad y deja toda demostración científica como cuestión formal, problema que Laporte recoge al decir:

"Dans tous ces textes, assurement, le critérium de l'evidence est donné comme garanti par la véracité divine. Mais comme la véracité divine nést elle-même établie que par une doublé démostration prouvant premièrement que Dieu existe, secondement qu'il n'est pas trompeur, et comme cette démonstration ne vaut qu'autant qu'elle est évidente, il s'ensuit, semble-t-il, que nous tournerons dans un cercle. ${ }^{36}$

Galileo entendía que había resuelto el problema de la relación entre la verdad formal y la objetiva mediante la matemática, pues ésta le permitía llegar a las cosas mismas y no quedarse en su superficie. Ese camino sigue Descartes, y es quién se da cuenta del escollo existente al intentar mostrar la validez filosófica del principio.

El proceso con que Descartes da inicio a su reflexión filosófica, lleva a pensar que se puede superar el problema reaplicando el proceso de duda sobre sí mismo, es decir, estableciendo como conclusión del proceso la reflexividad que permite la duda hiperbólica. Pero plantear como condición para llevar a cabo la reflexión la

\footnotetext{
36 "En todos los textos, evidentemente, el criterio de evidencia está establecido como garantía de la verdad divina. Pero como la veracidad divina no es establecida más que por una doble demostración probando primeramente que Dios existe, en segundo lugar que no es engañador, y como esta demostración no es válida más que en tanto que es evidente, se sigue, según parece, que nos movemos en un círculo". LAPORTE, J.: Op. Cit., p. 153.
} 
posibilidad de que exista un dios engañador, suscitó ya en su época la oposición de amigos y enemigos que le señalaron que esa condición era una ficción, es decir, que fingía un Dios burlador que no hacía ninguna falta. ${ }^{37}$ En este tema la tradición filosófica cartesiana atendió a las razones de Arnauld, y consideró fundamental el problema de la circulatio.

Descartes trato de solucionar el problema en las Respuestas a las Cuartas Objeciones, y en un texto, continuación del anteriormente citado, no sólo se defiende directamente de esta acusación, sino que también enfoca la solución al tema desde la percepción actual de las cosas y la percepción rememorada. El texto de las Respuestas a las Cuartas Objeciones dice:

"Por último, ya he explicado con bastante claridad en las respuestas a las segundas objeciones, número 3 y 4 , que no he incurrido en lo que llaman círculo, al decir que sólo estamos seguros de que las cosas que concebimos muy clara y distintamente son todas verdaderas, a causa de que Dios existe, y, a la vez que sólo estamos seguros de que Dios existe, a causa de que lo concebimos con gran claridad y distinción; pues ya entonces distinguí entre las cosas que concebimos, en efecto, muy claramente, y aquellas que recordamos haber concebido muy claramente en otro tiempo. En efecto: en primer lugar, estamos seguros de que Dios existe, porque atendemos a las razones que nos prueban su existencia; más tras esto, basta con que nos acordemos de haber concebido claramente una cosa, para estar seguros de que es cierta: y no bastaría con eso si no supiésemos que Dios existe y no puede engañarnos". ${ }^{38}$

Si se entiende que la fórmula cartesiana del cogito concuerda, por el recurso a la memoria y rememoración, con la formulación del cogito que realiza Sosias en el Anfitrión, como ésta, al incluir el reconocimiento de lo que era supone un yo biográfico, resulta que el cogito se presenta como el resultado de una reflexión sobre la historia, o al menos como una síntesis de hechos psíquicos, lo que no concuerda con la presentación del cogito hecha por el propio Descartes y, además, en este contexto no resuelve la cuestión, pues la rememoración pide también la garantía divina para lo rememorado. ${ }^{39}$

\footnotetext{
${ }^{37}$ Cfr.: DeSCARTES, R.: Meditaciones Metafísicas. (Segundas Objeciones), p. 104. A-T. VII, 137138.

${ }^{38}$ Descartes, R.: Meditaciones Metafísicas . (Cuartas Respuestas), p. 197. A-T. VII, 283-284.

${ }^{39}$ Históricamente es en la filosofía de Kant, al pasar del contexto cognoscitivo (en el que el yo puro de la apercepción constituye el fundamento suficiente para la objetividad del conocimiento) al yo práctico, en dónde se muestra la necesidad de entender éste (el yo práctico) como producto y
} 
No he visto que ningún autor, de los que he consultado, Liard, Hannequin, Gurtvich, Alquié, Boutroux, Geroult, Brunschvicg, Brochard, Koyré, Löwit, Lefêvre, haya resuelto el problema, sino que todos pasan como de puntillas sobre él, y admiten, pero sin mostrar la razón, que la verdad gnoseológica y la verdad divina coinciden. Es interesante, con relación a éste problema, el contraste que se produce entre la obra de Plauto y la de Descartes, pues mientras que en la de este último vemos que la solución a la veracidad divina está embarrancada en la petición de principio, en la obra de Plauto se soluciona por el mismo Júpiter, por su presencia y palabra dada a Anfitrión. Lo que lleva a recordar que Descartes, como tantas veces se le dijo en las objeciones, no veía la cara de Dios.

Considero que se puede plantear una solución al problema cartesiano a partir de la distinción que V. Peña realiza en el prólogo a su traducción de las Meditaciones Metafísicas, y que exige atender radicalmente a la ontología cartesiana y su relación con la teología para poder recoger el problema de la evidencia y la respuesta de Descartes a Arnauld. Sin embargo, y precisamente por la cuestión ontológica, el autor de la distinción entiende que conduce al reconocimiento de que es imposible salir del círculo:

"El círculo cartesiano sería, pues, el reconocimiento de que no hay claridad, desde que las cosas ontológicas se presentan con profundidad" ${ }^{40}$

La distinción afecta a la concepción de Dios, y reside en la necesidad de comprender a Dios de dos formas: 1. Como entendimiento garantía de la eternidad de las verdades (garantía de la existencia de la ciencia); conciencia lógica, que es mi misma conciencia lógica. 2. Como voluntad que me envuelve, y que es también garantía del conocimiento, pero en el sentido de que si lo que conozco es verdad, lo que conozco no es todo lo que se puede conocer. ${ }^{41}$

Si la distinción anterior puede dar lugar a plantear una solución al tema de la circulatio, es porque entender que la conciencia lógica pertenece tanto a Dios como al ser humano, lo que establece el razonamiento cartesiano es que la razón divina garante de la verdad y la humana están sujetas a las mismas condiciones: claridad y distinción, pues, salvando la infinitud divina, la concepción del entendimiento no difiere en ambos casos, lo que recoge perfectamente la

fundamento de la historia, pues darse el deber como principio moral supone un proceso histórico en el que interviene como causa.

\footnotetext{
${ }^{40}$ PEÑA, V.: Prólogo a las Meditaciones Metafísicas, p. LXI.

${ }^{41}$ Ver: PeÑA,V. : Prólogo a las Meditaciones Metafísicas, pp. XXXII a XLI.
} 
concepción de Descartes, como puede corroborarse, entre otros, en el siguiente texto:

"Pues confieso que aquí con franqueza que la idea que tenemos, por ejemplo, del entendimiento divino, no me parece diferir de la que tenemos de nuestro propio entendimiento, sino al modo como la idea de un número infinito difiere de la idea de un número binario o del ternario."42

De ahí, resulta la posibilidad de sostener que la claridad y distinción con que se concibe algo, como no difiere más que en su condición de infinito en Dios y en los hombres, permite afirmar la evidencia y verdad de lo percibido. Ahora bien, aceptar lo anterior, dado que la verdad que funda el principio de evidencia es temporal y dado que mi percepción ligada a mi ser no puede ser infinita, requiere responder a una nueva pregunta: ¿puede suponerse que la claridad y distinción es también condición de inmutabilidad y eternidad de la verdad?, pues puede suceder que perciba ahora esto de una manera, y en un momento posterior de otra forma. La pregunta que acuciantemente surge entonces nos vuelve al círculo: ¿puede Dios cambiar la verdad de las cosas?

Seguir el razonamiento cartesiano en sus argumentos principales permite establecer que: no somos perfectos, pero somos hechos a imagen divina, y tenemos en nuestro ser el vestigio del ser divino que nos creó. Nuestro entendimiento no es perfecto, no podemos percibir la infinitud, y no percibimos todas las cosas de manera evidente; hay cosas que concebimos de forma confusa. Nuestra voluntad es más amplia que nuestro entendimiento, de forma que puede llevarnos al error si precipita su juicio y afirma aquello que no percibe con claridad y distinción:

“...reconozco que no queremos algo sin haberlo conocido antes de algún modo, más niego que nuestro entender y nuestro querer tengan la misma extensión; pues es cierto que, a propósito de una misma cosa, podemos querer mucho y conocer muy poco". 43

De que mi voluntad se atenga a lo que el entendimiento le presenta con claridad y distinción depende que no haya error en mi conocimiento, y la garantía de ello es que la claridad y distinción pertenece también al entendimiento divino, pero como la voluntad divina me envuelve infinitamente de forma que lo que percibo clara $y$ distintamente puede ser ahora, pero no ser luego, no tengo garantía de que esto que percibo como verdad, luego no lo sea.

\footnotetext{
42 Descartes, R.: Meditaciones Metafísicas. (Segundas Respuestas), p.113. A-T. VII, 150-151.

${ }^{43}$ Descartes, R.: Meditaciones Metafísicas. (Quintas Respuestas), p. 297. A-T. VII, 440-441.
} 
Descartes supone que, al eliminar mediante la duda hiperbólica que haya un dios engañador, no hay engaño, de forma que si percibo algo como verdad, dado que mi conciencia lógica coincide con la divina, lo que percibo es verdad, puesto que, incluso aunque Él lo cambiara, por rememoración puedo afirmar que es verdad. Ahora bien, si Dios puede cambiar la verdad (es omnipotente), el ser humano por rememoración no puede afirmar que lo que percibe es verdad sino, todo lo más, que recuerda que lo fue, pues entonces no posee ninguna razón que le permita saber que existe relación efectiva actual entre su percepción clara y distinta y la del entendimiento divino. Entonces la pregunta que se ha de responder es: ¿existe alguna garantía de esta coincidencia? El razonamiento cartesiano muestra que esta garantía exige aceptar la existencia de verdades inmutables y eternas (ideas innatas y naturalezas simples), que es lo que constituye la diferencia entre el fingimiento de los poetas y su pensamiento, como se muestra en el siguiente texto:

"En cuanto a lo que decís que os resulta duro ver cómo se establece una cosa inmutable y eterna que no es Dios, tendríais razón si se tratase de algo existente, o si yo estableciera algo hasta tal punto inmutable, que su inmutabilidad misma no dependiera de Dios. Pero, así como los poetas fingen que los destinos han sido impuestos por Júpiter, pero, una vez establecidos, él mismo está obligado a respetarlos, así también pienso yo que las esencias de las cosas, y las verdades matemáticas, no es que sean independientes de Dios, pero como Dios lo ha querido y dispuesto así, son inmutables y eternas. Que eso os parezca duro de reconocer o blando, poco importa; me basta con que sea verdad". ${ }^{44}$

Los poetas fingen que los destinos dependen de Júpiter, y que éste se ve obligado por lo que él mismo como divinidad establece, es decir, que la razón que él mismo se da, y por la que algo es, le determina y limita. El filósofo racionalista piensa y afirma, no que Dios sea obligado por su razón, sino que su voluntad ha establecido verdades eternas, y que estas verdades no limitan la voluntad divina, ni la constriñen, ni la obligan, sino que ellas son su voluntad. Es decir, que las verdades eternas existen, y son así, eternas, porque si no lo fueran, tampoco existiría su voluntad eterna, ${ }^{45}$ por ello, se puede afirmar que mi pensamiento y todas aquellas cosas que demuestra clara y distintamente no tienen sólo realidad

${ }^{44}$ Descartes, R.: Meditaciones Metafísicas. (Quintas Respuestas), p. 299. A-T. VII, 443-444.

${ }^{45}$ Pensar que las ideas eternas pueden ser otras (o no-ser de alguna forma), dado el razonamiento anterior, sólo podría tener lugar suponiendo que Dios negara su propia voluntad, lo que es absolutamente contradictorio. 
formal, cognoscitiva, sino también realidad objetiva. ${ }^{46}$ De ahí que saber que lo que percibo es verdad no sólo requiere la justificación del principio por la demostración, sino mostrar su condición de naturaleza simple, de idea eterna o innata.

El problema de la veracidad divina no puede tener solución sin considerar el problema de la voluntad divina, de la que para Descartes, como para Suárez cuya obra cita expresamente ${ }^{47}$, depende la existencia de todo cuanto es. La obra de Descartes deja traslucir lo que el autor francés debe al jesuita español: la concepción de la voluntad de Dios, en la que aquél basó su veracidad. ${ }^{48}$ Por ello, puede concluirse que una consideración teatral o ficticia de la filosofía cartesiana sólo puede tener lugar atendiendo a su forma discursiva y polémica, no a su contenido filosófico, pues realmente Descartes sabía que tenía ante sí un problema muy serio: si era posible mostrar la existencia de la verdad en sentido fuerte, como predicado ontológico, y encontró y puso todos los elementos necesarios para resolverlo.

\section{LA HISTORIA DE LA FILOSOFÍA, EL PENSAMIENTO CARTESIANO Y SUS FUENTES}

No cabe duda de que a Plauto, tras la exposición que el Dr. García Hernández

\footnotetext{
46 "Por realidad objetiva de una idea, entiendo el ser o la entidad de la cosa representada por la idea, en cuanto esta entidad está en la idea; y en el mismo sentido puede hablarse de una perfección objetiva, un artificio objetivo, etc. Pues todo cuanto concebimos que está en los objetos de las ideas, está también objetivamente, o por representación, en las ideas mismas. DESCARTES, R.: Meditaciones Metafísicas. (Quintas Respuestas), p. 129-130. A-T. VII, 179-180.

47 Descartes realiza en las Respuestas a las Cuartas Objeciones una referencia expresa a la Disputación 9, Sección 2, n.4 de Suárez, pero no tiene nada que ver con el problema de la relación entre la voluntad y la razón divinas, sino con el uso de la expresión materialmente. Ahora bien, también indica que entre las pocas lecturas de filosofía que ha hecho está la de este gran filósofo español. Cfr.: DeSCARTES, R.: Meditaciones Metafísicas. (Cuartas Respuestas) p. 190. A-T. VII, 270271.

48 Considero que la solución al problema de la veracidad divina remite en Descartes a la concepción de la voluntad de las Disputaciones Metafísicas de Francisco Suárez., de las que debió tener un conocimiento mucho mayor que el que reconoce. No es posible explicar en una nota cómo concibe Suárez la voluntad de Dios, pero se pude señalar que Suárez prima la voluntad divina (libertad) sosteniendo que el querer de Dios es esencialmente su ser mismo. Pero, teniendo en cuenta que en el obrar divino se unifican entendimiento y voluntad, pues de otra forma su ser sería contradictorio. La voluntad divina obra de forma libre e inmutable, opera las cosas que quiere y quiere las cosas que opera, pues la libertad de la voluntad está perfectamente armonizada con su inmutabilidad. Por ello, el acto de la voluntad divina es absolutamente libre, necesario e inmutable, mientras que la del ser humano es libre, pero hipotético. Cfr. SuÁrEZ, F. (1962). Disputaciones Metafísicas. Dip. XXX, vol. IV. Madrid: Gredos.
} 
lleva a cabo en este libro, hay que considerarlo fuente para el conocimiento del sistema cartesiano, pero el problema es cómo considerar esta fuente y, en general, todas aquellas que siguen su misma pauta. Considero que respecto del sistema cartesiano esta obra tiene que descartarse como fuente en el sentido técnicofilosófico, y no puede considerarse como fuente histórico-filosófica-cultural, sino que hay que considerarla como una fuente histórico-filológica-cultural, pues utiliza los análisis técnico-filológicos de la filosofía cartesiana para subordinarla a una de las formas culturales, el teatro, presentes en la mentalidad de la época, pero no influye en su contenido filosófico.

No aceptar la obra de Plauto como influencia filosófica, aunque la filosofía sea también una forma cultural, tiene lugar, además, en cuanto en ella no se formulan conceptos filosóficos, y, si puede considerarse que ejerce los cartesianos, es tras conocer la filosofía de Descartes, lo que es importante para saber si considerarla fuente externa o interna.

En la tesitura de dirimir sobre esta alternativa, considero que tiene que entenderse como fuente externa, por tanto, como una fuente a partir de la que, por ejemplo, se puede dar cuenta de cómo se generó una tradición relativa a técnicashistórico-filológicas que permiten la restitución de los textos, así como mostrar la forma de desbrozar la acumulación de temas que permiten consolidarla, y ordenarlos con vistas a la clasificación de la información generada.

El trabajo filológico que tiene lugar en el libro trata de mostrar que la obra de Descartes debe tanto a la de Plauto, que su lectura es imposible sin aquella, pues realmente reproduce continuamente sus esquemas. Por ello, hay que considerar que la pretensión del autor es que la obra de Plauto se entienda como una fuente interna del sistema cartesiano, como una influencia fundamental en el sentido de Brehier, es decir, como una información eficaz para comprender su sistema. En este sentido pueden entenderse multitud de afirmaciones que permiten pensar que la obra cartesiana es simplemente una transposición lingüística de la obra de Plauto, una de ellas es la siguiente:

"Descartes ha reemplazado las frases simples de Plauto por subordinadas de relativo". 49

¿Puede esto llevar a suponer que se puede explicar a Descartes por Plauto? Considero que afirmar esto sería practicar una reducción a las fuentes, a la que no es ajena en ningún caso la Historia de la Filosofía, pero que lleva a una nivelación

${ }^{49}$ GarCía HernándeZ, B.: Op. Cit., p. 104. 
de toda idea que constituye la negación de la Filosofía misma, como ya hicieron Wolfson con Spinoza, o Coplestón con la Filosofía Crítica de Kant. El problema en estos casos es que se pierde la razón interna de la obra de un autor, su verdad intrínseca, en función de sus fuentes, y, de esta forma, cuando se trata de mostrar la aportación de esa filosofía a la Historia, resulta que ésta no existe. Con ello se genera una contradicción, porque la aportación realmente existe: si Descartes no hubiera escrito su obra, nunca se habría hablado de Racionalismo; si Kant no hubiera escrito la suya, nunca se habría hablado de Filosofía Crítica.

Hay quien supone que estas designaciones son constantes históricas, y que esto permite obviar el problema. Lo que no puede olvidarse es que lo que estos estudiosos llaman constantes históricas se generan por la obra filosófica de un autor, y que su determinación como constante histórica tiene que hacerse con las salvedades que cada caso exija (para no incurrir en anacronismos), y siempre teniendo y presentando como término de comparación la filosofía que la ha producido.

Ciertamente, como bien se señala en el libro, una obra no puede tomarse como la única inspiradora de un sistema filosófico, más bien hay diversas líneas de tradición que van generando la posibilidad de pensar de una forma. Por ello, hemos de considerar que las diversas fuentes que pueden establecerse como influyentes en el pensamiento de un filósofo, nunca podrán alcanzar más que la consideración de ser un estudio genealógico, un estudio del pasado de los elementos de un sistema, pero nunca extraer de ellas la razón interna del sistema. De ahí, que la razón interna de una filosofía, su justificación, no se encuentre reduciéndola a sus fuentes, sino en la conexión de ideas con que dio cuenta de los problemas presentes en los ámbitos científico y cultural del contexto histórico al que pertenece, así como en las obras y acciones que permite y a las que ha dado lugar.

Ahora bien, entre las fuentes y los contextos científicos y culturales hay una realimentación, pues las fuentes tienen una virtud: poder saber sobre la realidad de aquellos contextos históricos en que se hacen patentes los problemas no resueltos, y poder buscar los métodos a seguir, pero nunca puede llevarse su importancia hasta el extremo de reducir a ellas las obras, pues de esa manera se pierde tanto el criterio de originalidad, como el de identidad, en favor de los de acumulación y continuidad. Ciertamente la Historia de la Filosofía no es nada sin ambos, pues la originalidad no nace sino como síntesis reflexiva sobre el trabajo acumulado, y éste trabajo, muchas veces realizado por generaciones, no puede tampoco supeditarse a la originalidad de una producción filosófica de forma que ésta sea la única que da lugar a la Historia. Si negamos esto, y entendemos la Historia de la Filosofía sólo desde la obra paradigmática, estamos en el caso inverso al de reducción a las 
fuentes, que puede llevar hasta aceptar que desde un sistema puede darse cuenta de la Historia de la Filosofía, lo que es tanto como eliminar el carácter propio de esta disciplina: el de ser el lugar de la autorreflexión, es decir, el lugar en que la filosofía reflexiona libremente sobre sí misma en busca de nuevas formas de entender y conceptuar los problemas que afectan al ser humano, así como de nuevas formas y métodos de solución a problemas no resueltos.

El ser humano no produce nada de la nada, sin fructificación de las variaciones acumuladas en un orden conceptual que permita repensar el pasado, no hay Historia, y sin ella tampoco hay posibilidad de tomar conciencia de en qué consiste la razón, ni la libertad, ni el ser humano, ni nada. Pero, sin capacidad de autorreflexión, es decir, de reflexión y contrastación filosófica sobre lo que se ha hecho histórico-filosóficamente, no puede tener lugar un desarrollo del conocimiento que, además, pueda ser justificado críticamente, por tanto, no puede tener lugar el desarrollo y progreso de un conocimiento libre.

Hechas estas salvedades es necesario decir que el libro que consideramos presenta una fuente que abre el planteamiento cartesiano a un contexto filológicocultural importante, en el que constituye un elemento, que no es simplemente una anécdota, sino un elemento evidentemente relevante para el mejor conocimiento de las influencias que obraron en su contexto cultural sobre este pensamiento, y que puede dar lugar a nuevas formas de reflexión filosófica.

\section{CONCLUSIÓN: EL HUMANISMO CARTESIANO}

La obra de Descartes es muy simple en su apariencia. Tanto por su lenguaje, como por su forma expositiva, se muestra muy asequible a la lectura de cualquiera, incluso de los que no conocen nada de filosofía. Seguramente esta consideración resulta más aplicable al Discurso del Método que a las Meditaciones Metafísicas, pero no por el tema y lenguaje, sino más bien por las resonancias e implicaciones del título de esta obra.

En el Discurso, Descartes abandona todas las formas típicas de exposición filosófica, que son en ese momento las escolásticas disputadas o las renacentistas dialogadas a la manera Galileo en el Diálogo sobre los dos máximos sistemas del mundo, y se suma a la exposición de tipo pictórico que defendía Montaigne en sus Essais. Abandona la forma de exposición escolástica, dogmática y de defensa doctrinal, y abandona la forma comunicativa en que en un diálogo se trata de convencer sobre la necesidad de un nuevo principio, o de llegar a un acuerdo sobre como aceptarlo. Lo que lleva a cabo es simplemente el retrato de un ser humano: lo que ha sido y significado para él la formación educativa que ha recibido, los problemas vitales e intelectuales que ha tenido y cómo ha descubierto un principio 
que le permite entenderlos, dar cuenta de ellos, y formular un método que aplicado a las ciencias que haga posible su progreso.

Esta forma expositiva fue muy frecuente entre los escépticos, es decir, entre aquellos investigadores e intelectuales que, no estando de acuerdo con las tesis escolásticas, sin embargo tampoco veían que el nuevo camino abierto por la ciencia fuera seguro, y pensaban que era preciso apegarse a la tesis de que si los principios escolásticos resultaban inaceptables (en algunos casos increíbles), tampoco había otros principios en que apoyar con firmeza una nueva concepción; este no es sólo el caso de Montaigne que se inclina decididamente a intentar promover la unidad entre los seres humanos por la vía de comunicarse sus intereses y vicisitudes, sino también la de Francisco Sánchez cuando en su Quod nihil scitur, sin prescindir de la problemática escolástica, sino al contrario usando su misma terminología, expone las razones por las que la teoría aristotélico-escolástica no es digna de crédito, pero también las deficiencias de las demostraciones matemáticas $\mathrm{y}$, por tanto, su incapacidad como ciencia para fundar una verdad que permita consolidar la validez del conocimiento.

Descartes adopta esta misma forma, nos cuenta sus vicisitudes, las deficiencias de la enseñanza recibida, pero ya no es un escéptico, pues no sólo ha resuelto un problema matemático, sino que también descubre una nueva verdad filosófica que le permite establecer con seguridad la objetividad de la razón como unidad metodológica.

Evidentemente, el modo en que tiene lugar la presentación de la primera verdad da pie a su consideración desde el teatro, y la ficción literaria; en este sentido es muy significativa su forma de proceder, pues la total y absoluta humildad con que la presenta, tiene el efecto contrario del que se muestra en su literalidad: tiene un efecto burlesco, de ficción. A un lector algo conocedor de la filosofía y su lenguaje técnico, lo primero que le choca es el uso coloquial, en muchos casos totalmente, que hace de dicha terminología, y le choca más aún que en su polémica con los principales filósofos de la época: Hobbes, Gassendi, Mersenne, etc., cuyas objeciones muestran claramente que le reconocen como filósofo y que reconocen que sus problemas son filosóficos, y dignos de atención, diga que no sabe nada, o muy poco, de filosofía:

"Mi mayor temor podría ser que, no habiendo empleado nunca mucho tiempo en leer libros de los filósofos, acaso no hubiera seguido exactamente su manera de hablar...". 50

${ }^{50}$ Descartes, R.: Meditaciones Metafísicas. (Cuartas Respuestas), p. 190. A-T. VII, 270-271. 
He señalado que la forma expositiva que adopta no era inusual en la época y que era la propia de los escépticos, pero si atendemos no solo a la discusión sobre su condición escéptica (su lugar clásico es la duda), sino también a si la usa como un disfraz o una máscara para convencer, nos encontramos que, en su literalidad, Descartes ni trata de convencer, ni siquiera de dar lugar a que se piense que el método o las convicciones filosóficas que presenta se incardinan en el bien común, o tratan de orientarlo hacia ellas, sino que es una ocurrencia propia de un soñador que no pretende alcanzar ningún poder, ni condición social, ni personalmente responde a un acto de soberbia o exhibición de sabiduría, aunque si cree firmemente en la capacidad de su descubrimiento para trabajar en las ciencias, pues éstas sólo pueden progresar con un sólido fundamento filosófico y metodológico como el que ha descubierto y que, por ello, se propone llevarlo a la práctica.

El modo coloquial que usa en el Discurso del Método, y que adquiere en las Meditaciones Metafísicas la forma de una completa humildad solidaria del reconocimiento de que como ser humano es imperfecto y puede equivocarse, cambia totalmente en las Respuestas a las Objeciones, donde muestra que no tiene inhibición alguna para cortar las respuestas agresivas o burlescas, para usar la retórica, y que tiene un conocimiento completo de todos los recursos filosóficos que se usaban en la época, en fin, que respeta a sus adversarios, pero pide el mismo respeto para sus tesis y persona.

¿Era así la personalidad de Descartes?, ¿son las formas de la época?, ¿tenía que demostrar que tenía tanto ingenio y capacidad polémica y retórica como sus adversarios? Sobre esto siempre se puede discurrir, y constituir hipótesis interesantes, lo cierto es que la forma de exposición que Descartes adopta, da lugar a una nueva forma de trabajo filosófico y científico, que logra que se acepte en su época, y que ya ha dado lugar hasta la actualidad a numerosos debates. Este trabajo era nuevo en su momento, pues no lo amparaba ninguna escuela ni poder instaurado (realeza, iglesia), y tampoco pretendió fundar escuela con él, sino que lo mismo que en la narración sólo se apoya sobre sus propias experiencias y conocimientos, también sólo considera que tiene que decirlo por si a algún otro estudioso o científico puede servirle para algo. ${ }^{51}$

${ }^{51}$ En el Renacimiento, en el Barroco y en los comienzos de la Edad Moderna, el saber estaba ligado a escuelas (puede recordarse la Escuela de Florencia y la de Padua), a Universidades y a los poderes efectivos nobleza, realeza e Iglesia. También estaba unido a los círculos más o menos oficiales, o a círculos generados como reacción al saber oficial, cuyos factores detonantes más señalados eran la lengua (que dio lugar a la aparición de centros como el Gresham College) y las disputas sobre el método. Entre los círculos más conocidos estaban el de Gassendi, y otros como los círculos paracelsianos de Londres, los rosacrucistas y en general todos los que dieron lugar a la 
La confianza de Descartes en su método, que es confianza en la ciencia, trasluce una postura humanista, que ya no es la exaltación del ser humano renacentista, que como en la obra de G. Bruno le considera capaz de alcanzar el saber total, o como en la de Pico della Mirandola le muestra como el único ser en la naturaleza cuya voluntad le permite ser lo que quiera. ${ }^{52}$ El humanismo cartesiano va unido a la confianza en que el ser humano puede conocer la verdad, pues su razón, solidaria del método, puede producir conocimientos verdaderos que permitan el progreso de la ciencia, y que sean útiles.

En las Respuestas a las Objeciones, sobre todo a las de Gassendi (Quintas) y Bourdin (Séptimas), el tono general es polémico y teatral. Descartes increpa a sus objetores con relación al modo y artilugios retóricos que emplean, y les acusa de fabricarse sombras inexistentes. En las Respuestas a las Séptimas Objeciones, Descartes que actúa como un maestro en la esgrima dialéctica, no solo se dirige a Bourdin poniendo de manifiesto y rechazando su forma burlesca y teatral, así como su intención de asimilar su filosofía a esa misma condición, sino que también le critica que no intente como él eliminar todas las sombras (todo lo que aprendió), para buscar una razón a partir de la que poder decidir qué es verdad y qué no lo es. $^{53}$

Ciertamente la argumentación cartesiana contra Bourdin resulta muy teatral, también es cierto que el teatro es una de las formas de expresión artísticas que más frecuentemente se han usado para dar cuenta de la realidad humana, y que Descartes sigue sus fórmulas en sus respuestas muchas veces, como sucede en sus respuestas a Gassendi cuando dice:

"Hasta aquí ha hablado el espíritu con la carne, y, como era justo, ha disentido de ellas en muchos puntos. Ahora levanto la máscara y reconozco que hablo en realidad al señor Gassendi, persona tan estimable por la

llamada filosofía oculta. Es bien sabido que si de algunos resultaron formaciones científicas importantes, como del que se reunía en la Red Bull Tabern, en Londres, que dio lugar a la Royal Society, otros como los Rosacruces influyeron fuerte y decididamente en la política centro europea contra los Habsburgo. Ciertamente en el caso de Descartes se ha señalado muchas veces su proximidad a los Rosacruces y, claro está, era conocido en los círculos filosóficos de la Haya y París. Pero, lo que constituye la novedad de su exposición no sólo es que no muestre su relación o pertenencia a ningún círculo, sino que además no se presente como el gran inventor de algo, lo que era muy importante, el anhelo de todo pensador, la forma de obtener reconocimiento y fama.

52 Cfr.: BRUnO, G (1987). Los heroicos furores. Madrid: Tecnos. Igualmente: PICO DELLA Mirandola (1993). El discurso sobre la dignidad del hombre. En: SANTIDRIÁn, P. (1993) Humanismo y Renacimiento. Madrid: Alianza Editorial, pp. 121-153.

${ }^{53}$ Cfr.: Descartes, R.: Meditaciones Metafísicas. (Séptimas Objeciones), pp. 389-390. A-T. VII, Oo, pp. 511-512. 
integridad y honestidad de su espíritu como por la profundidad y sutileza de su doctrina, y cuya amistad, siéndome muy cara, me esforzaré por merecer." 54

Si resulta imposible aceptar que la obra de Descartes sea una representación, no es porque el teatro le disgustara, no lo conociera, o porque no haya seres humanos que realicen su vida como representación, sino porque parte de un principio que trasciende esta forma de vivir y entender la vida, y es que incluso en el caso de que el mundo sea un Gran Teatro, y que la vida y acción humana sólo sea una representación, ésta no sería como es si el ser humano no encuentra una razón para creerla y seguirla, como expone en el siguiente texto:

“...afirmo que el pensamiento de cada cual, es decir, la percepción o conocimiento que tiene de una cosa, debe ser para él la regla de la verdad de dicha cosa: es decir, que todos los juicios que hace han de ser conformes a tal percepción para ser buenos. Y hasta cuando se trata de las verdades de fe, debe percibir alguna razón para reconocer que han sido reveladas por Dios, antes de decidirnos a creerlas. “ ${ }^{\text {}} 55$

El principio filosófico que late en la filosofía cartesiana: que la razón es la base de la vida y acción humana, sobrepasa la discusión sobre si ésta es o no una representación, al igual que la de si la obra cartesiana trascurre según los cánones establecidos por una obra teatral u otra. Por ello, sin restar mérito a la búsqueda de fuentes filológicas, considero que es preciso atender a su lugar en el contexto histórico-filosófico.

\section{BIBLIOGRAFÍA}

Alquié, F. (1966). La Découverte Métaphysique De l'Homme Chez Descartes. Presses Universitiaires De France

Boutrox, E. (1927). Des Vérités Éternelles Chez Descartes. Paris: Alcan

BrunschVicG, L. (1995). Descartes et Pascal lecteurs de Montaigne. Paris: Pocket 1995

DESCARTES, R. (1981). Discurso del Método, p. 25. Madrid: Alfaguara.

DESCARTES, R. (1977). Meditaciones Metafísicas. Madrid: Alfaguara

GARCía HernándeZ, B. (1997). Plauto y Descartes. Madrid: Tecnos.

Gouhier, H. (1962). La pensée métaphysique de Descartes. Paris: Vrin.

Gueroult, M. (1953). Descartes selon l'ordre des raisons. 2. Vols. Paris: Aubier.

Hannequin, A. (1908). Études d'Histoire des sciences et d'Histoire de la Philosophie.

París: Alcan.

\footnotetext{
54 Ibid. (Quintas Respuestas), p. 305. A-T. VII, 453-454.

55 Ibid. (Carta del Señor Descartes al Señor Clerselier), p. 309.
} 
LAfuente, M. I. (1987). Teoría y Metodología de la Historia de la Filosofía. Universidad de León: Contextos.

LEROY, M. (1930). Descartes: El filósofo enmascarado. Madrid: Espasa-Calpe. 